\title{
Per a què serveix un sincrotró?
}

\author{
Joan Sola \\ Departament de Química, Unitat de Q. Inorgànica, Facultat de Ciències. UAB \\ Joan Aliberas \\ IES Josep Puig i Cadafalch. Mataró
}

La construcció d'un modern sincrotró a Cerdanyola del Vallès costarà molts diners a la hisenda pública. Hem de tenir arguments per a respondre quan els nostres alumnes ens facin preguntes com ara: què és un sincrotró ? Per a què serveix ? Està justificada, aquesta despesa?

Està previst que l'any 2009 comenci a funcionar a Cerdanyola del Vallès el Laboratori de Llum de Sincrotró, el primer que es construeix al sud-oest d'Europa (fig. 1).

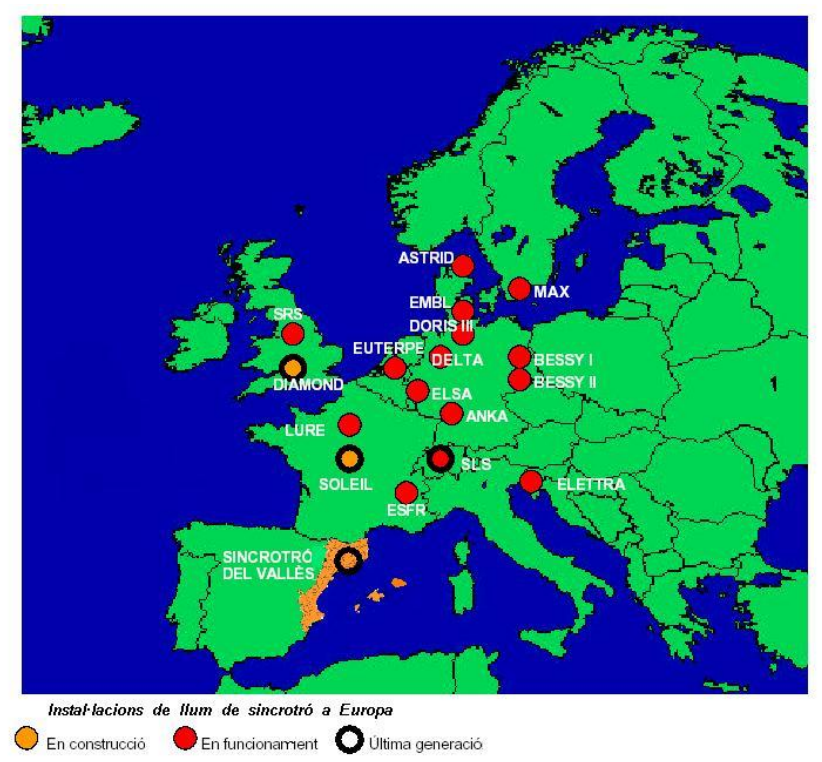

Fig. 1. Instal-lacions de llum de sincrotró a Europa

Ja fa anys que s'està promovent aquest projecte (fig. 2). El 1993 la Generalitat se'l va fer seu, i hi va gastar 1,8 milions d'euros fins a l'any 2002, quan el consell de ministres va aprovar la seva construcció, finançada a parts iguals pel govern central i la Generalitat. Construir-lo i posar-lo en marxa costarà en total uns 164 milions d'euros.

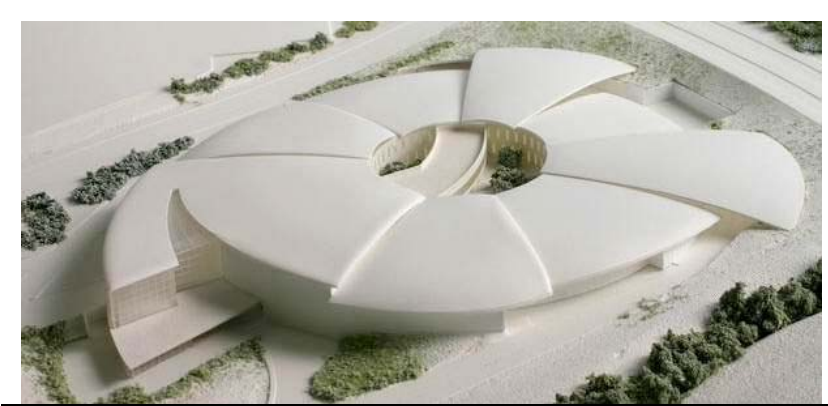

Fig. 2. Maqueta de l'edifici del Sincrotró de Cerdanyola (ALBA)

\section{QUĖ ÉS UN SINCROTRÓ?}

Originalment els sincrotrons es construïen com a acceleradors de partícules elementals per poder estudiar el seu comportament en fer-les xocar. Mantenir els electrons en una trajectòria circular permetia dotar-los de més velocitat i energia que en els acceleradors lineals.

La radiació de sincrotró es descobrí el 1947. Quan els electrons, movent-se a velocitats properes a la de la llum, són desviats (que vol dir sotmesos a una acceleració centrípeta), emeten un feix de radiació electromagnètica en direcció tangencial a la seva trajectòria. Les propietats d'aquesta radiació van resultar molt interessants: el seu espectre és continu, s'estén des de l'infraroig i visible fins als raigs $X$, i té unes característiques molt semblants a la radiació làser (feix extremadament col-limat, amb un angle d'obertura d'uns $10^{-5}$ radiants, polaritzada en el pla de l'òrbita). A més a més, la radiació és tan intensa que la llum de raigs $X$ de sincrotró equival a $10^{12}$ vegades la intensitat d'una làmpada convencional de raigs $X$ de les usades per fer radiografies. 
Les singulars característiques d'aquesta radiació van fer pensar en la possibilitat d'utilitzar-la per dur a terme estudis experimentals molt diversos, especialment, els relacionats amb l'estructura cristal-lina i molecular de materials minerals, biològics o sintètics, cosa que es va fer a partir de 1963.

Els sincrotrons de segona generació, dissenyats específicament per aprofitar la radiació de sincrotró, es construïren a partir de 1977. Els de tercera generació, com el que es farà a Catalunya, ja han estat especialment pensats per aconseguir que els feixos de llum resultin encara més intensos i col-limats. Més endavant veurem de quina manera.

\section{COM FUNCIONA?}

Els electrons es produeixen semblantment al tub de raigs catòdics d'un televisor. Mitjançant un càtode escalfat i una diferència de potencial (canó d'electrons) s'obté un feix d'electrons tan fi com un cabell humà. Tot seguit, el camp elèctric variable d'un accelerador lineal augmenta la seva velocitat fins a prop de la velocitat de la llum. A la sortida, els electrons, que tenen una energia d'uns $0,2 \mathrm{GeV}$ (1 giga $=10^{9}$ ), passen a l'anomenada anella d'injecció, on encara són accelerats fins a uns 2,9 GeV. Finalment són transferits a l'anella principal (anella d'emmagatzematge) (fig 3). Amb aquesta energia ja és possible obtenir radiació de sincrotró que abasta una zona espectral des de l'infraroig fins als raigs $X$ durs.

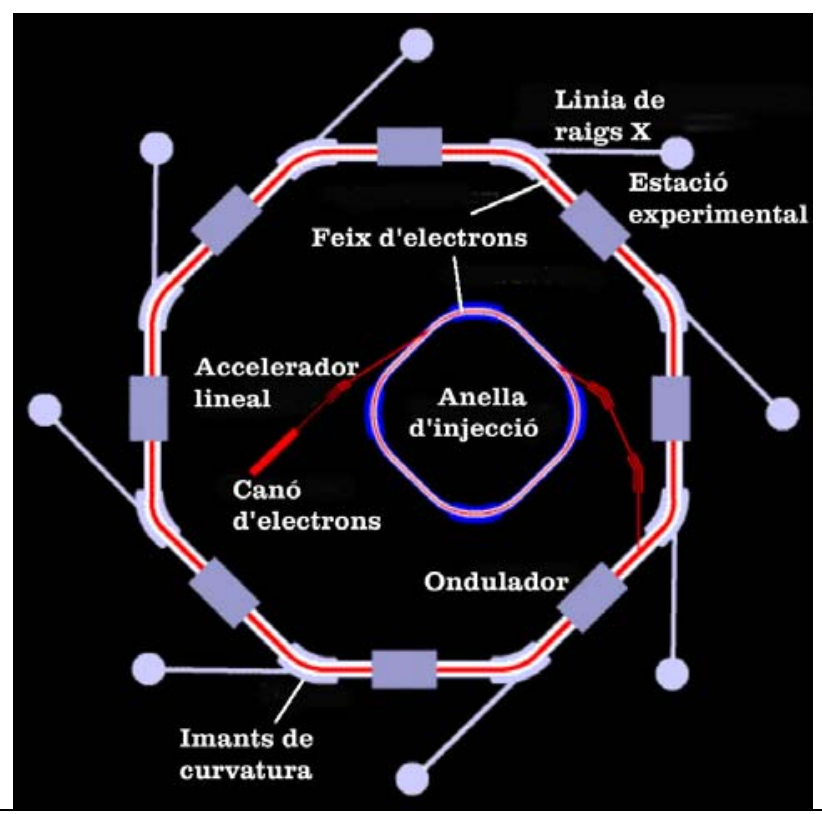

Fig. 3. Parts principals d'un sincrotró.

Per a desviar els electrons de la seva trajectòria recta inicial, tot mantenint-los en un pla horitzontal, s'utilitzen electroimants amb el seu camp magnètic dirigit verticalment. La desviació, prevista per la coneguda llei de la mà esquerra, es produeix en els imants de curvatura i en resulta una trajectòria circular dins dels imants, però en línia recta fora d'ells.

El feix d'electrons s'ha de mantenir enfocat dins d'uns límits molt precisos. Això s'aconsegueix mitjançant sèries d'imants quadripolars controlats automàticament per ordinador, igual que tota la resta de components del sistema.

En els sincrotrons de tercera generació s'hi han inserit unes sèries d'electroimants de polaritats alternants, anomenades onduladors. Al seu interior s'hi origina tot un seguit de camps magnètics de direccions alternades (fig. 4), que van desviant successivament els electrons ara en una direcció, ara en la seva oposada, tot sotmetent-los a una mena de sacsejada horitzontalment. A cada desviació els electrons emeten radiació cap endavant, radiació que es va sumant constructivament en cada petita ondulació, intensificant-se molt el raig lluminós i alhora fent-se molt més fi, és a dir, molt més brillant.
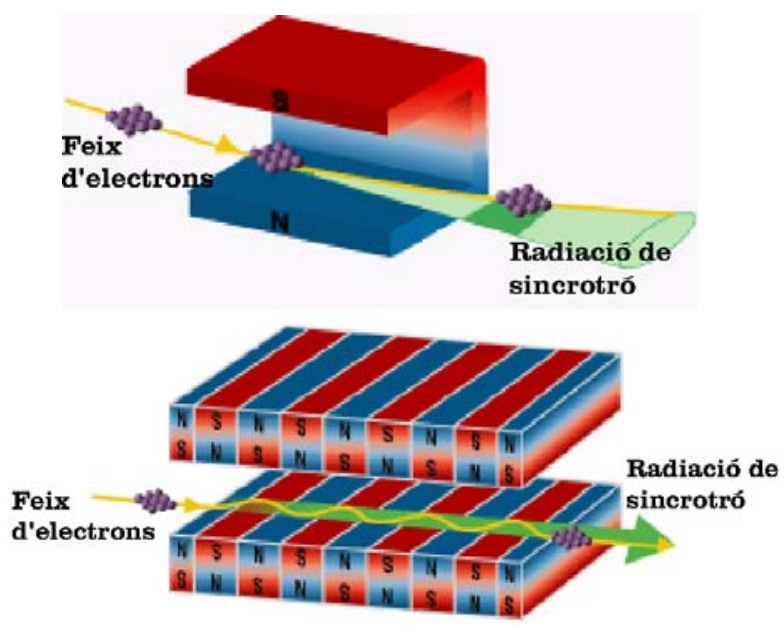

Fig. 4. Comparació del feix de llum produït en un imant de curvatura (a dalt) i en un ondulador (a baix), molt més intens i concentrat en el segon cas.

Per evitar el xoc dels electrons amb molècules de l'aire, que provocaria la seva aniquilació, a l'interior del tub s'ha creat un nivell de buit molt elevat (d'uns $10^{-10} \mathrm{mb}$, que equival a unes $10^{-13}$ vegades la pressió atmosfèrica normal, i que correspon a la categoria de buit ultraalt).

Tot i que en la figura 2 no s'hi han dibuixat, en diversos llocs de l'anella d'emmagatzematge hi ha unes cavitats acceleradores que utilitzen radiofreqüència per restituir al feix l'energia perduda en emetre la llum de sincrotró).

El feix d'electrons circula per un tub metàl-lic aïllat en un túnel de formigó, amb parets de 50 a 150 $\mathrm{cm}$ de gruix i de $70 \mathrm{~cm}$ en el sostre. Algunes de les parets estan recobertes, a més, amb un gruix de 20 $\mathrm{cm}$ de plom. Es tracta de mesures de seguretat per garantir que la radiació emesa, i que no s'utilitza experimentalment, quedi absorbida a les parets i no pugui traspassar a l'exterior del sistema. 


\section{EL TREBALL EN LES LÍNIES DE LLUM}

La forma de l'anella d'emmagatzematge és, doncs, poligonal. La desviació produïda a cada vèrtex pels imants de curvatura i, sobretot, l'acció dels onduladors, genera un feix de llum de sincrotró que segueix una direcció tangencial a la del feix d'electrons i que s'anomena línia de llum.

Per això a cada vèrtex i en direcció tangencial al feix, s'hi pot instal-lar, en principi, una estació experimental per aprofitar cadascuna de les línies de llum originades en cadascun dels imants de curvatura. Cada estació experimental està composta per tres cambres (fig 5).

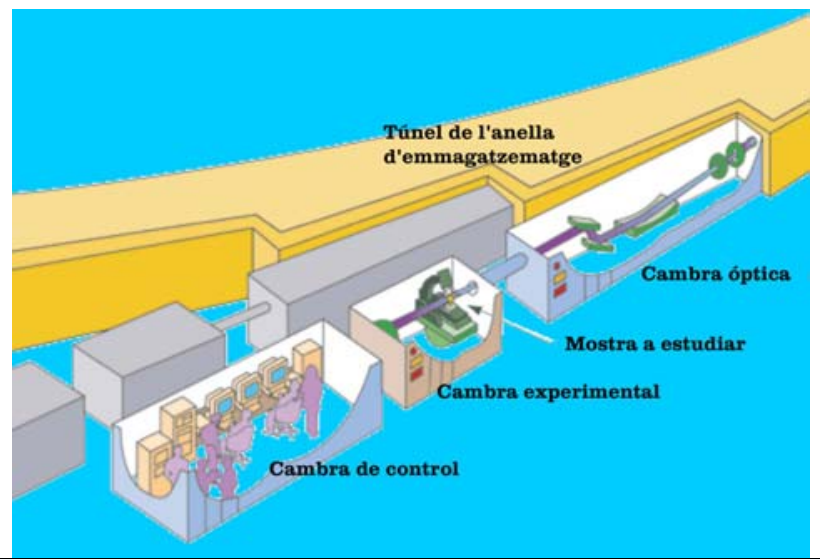

Fig. 5. Cambres a cadascuna de les línies de llum.

La línia de llum penetra primer en l'anomenada cambra òptica, on el raig s'enfoca i se li separen les radiacions que no interessen (monocromador).

La llum penetra després en la cambra experimental, on interacciona amb el material a estudiar. La mateixa cambra conté els corresponents detectors de la radiació resultant de la interacció.

En aquestes dues cambres no pot haver-hi persones mentre la línia està en funcionament. La raó és l'elevada quantitat d'energia que transporta la radiació. Per absorbir-la, les parets d'aquestes dues primeres cambres estan molt blindades: amb planxes d'acer revestides amb planxes de plom, de $6 \mathrm{~mm}$ de gruix. Després d'interaccionar amb la mostra, el feix de llum és finalment absorbit fent-lo incidir sobre un cilindre de plom de $13 \mathrm{~cm}$ de gruix.

Finalment, a la darrera de les cambres, lliure de radiació, se situen els tècnics que controlen la línia de llum i l'experiment que s'hi duu a terme. És la cambra de control.

\section{PER A QUÈ SERVEIX?}

Una de les aplicacions del sincrotró, potser una de les més significatives, és la determinació de l'estructura cristal-lina i molecular de materials, prèviament cristal-litzats en forma de monocristalls, mitjançant la tècnica de difracció de raigs $X$.

Quan un feix monocromàtic d'aquesta radiació incideix en un cristall, es difracta en unes determinades direccions i no pas en d'altres. El motiu d'aquest fet és que només en aquelles direccions en què es compleix la llei de Bragg (fig. 6), es sumen efectivament les intensitats i s'originen taques de llum en un detector (fotogràfic o electrònic), mentre que en les altres direccions les ones es destrueixen mútuament i originen zones d'ombra (intensitat nul·la).

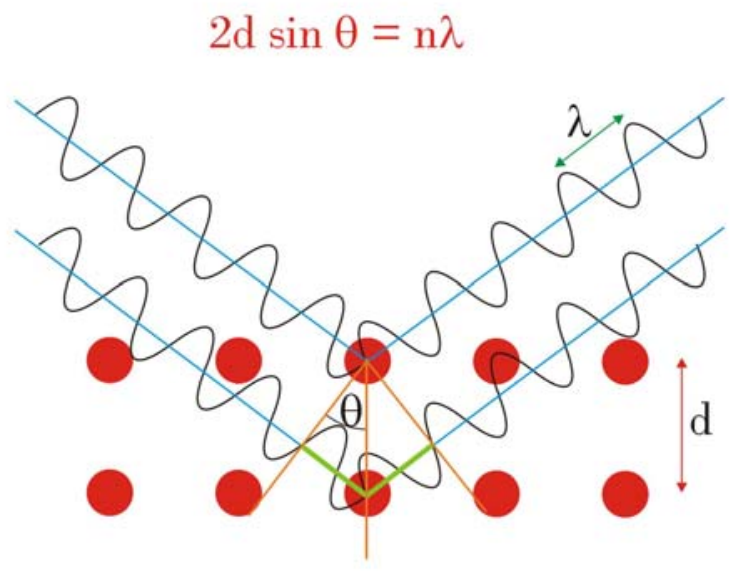

Fig. 6. En la situació mostrada en aquest reticle cristal.lí es compleix la llei de Bragg (fórmula superior). Quan la diferència de distàncies recorregudes pels dos raigs de llum (indicada en color verd) és un múltiple de la longitud d'ona, la interferència esdevé constructiva.

Tot fent girar un monocristall al voltant d'un eix determinat mentre incideix en ell un feix de raigs $X$, i enregistrant alhora les reflexions (que segueixen totes les llei de Bragg) en paper fotogràfic s'obtenen figures de difracció com la reproduïda aquí (fig. 7). L'ordenació dels àtoms en els cristalls determina múltiples plans on les ones es poden reflectir constructivament, originant les diverses taques de la figura de difracció. A partir de la posició de les taques es pot obtenir una estimació d'alguns paràmetres bàsics (angles i distàncies) del cristall.

El mateix fenomen s'utilitza per a construir monocromadors: de les diverses longituds d'ona que componen un feix de radiació, només la que satisfà l'equació de reflexió de Bragg en pot emergir en una direcció determinada amb prou intensitat. 


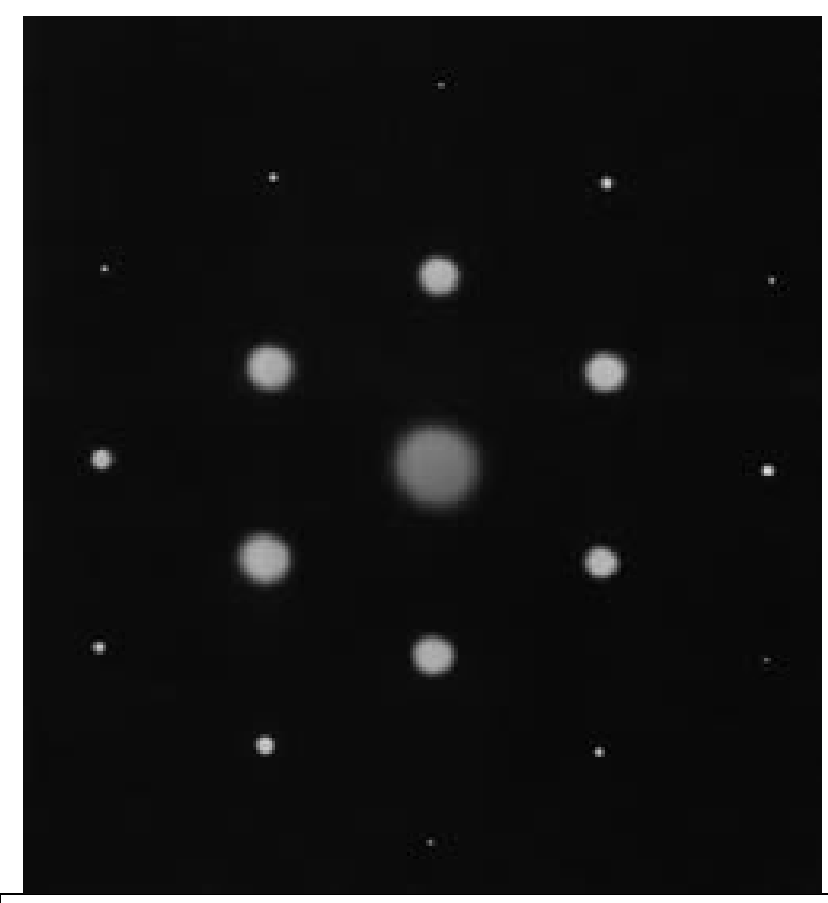

Fig. 7. Figura de difracció obtinguda a partir d'un monocristall de silici (Universitat d'Arizona).

D'altra banda, un experiment semblant però molt més complet, en què es mesura de manera quantitativa la intensitat de les reflexions mitjançant un difractòmetre automàtic de raigs $X$ instal.lat a la cambra experimental i comandat des de la cambra de control, permet anar molt més enllà.

Fent girar un monocristall entorn d'un eix vertical i dos eixos variables per a anar-lo orientant de moltes maneres diferents $i$ enregistrant electrònicament, per a cadascuna de les orientacions, la intensitat del feix reflectit segons la llei de Bragg, s'obtenen automàticament en un sol experiment desenes de milers de parelles de mesures orientació/intensitat. Un cop processades per ordinador permeten determinar l'estructura del cristall, és a dir, les posicions dels seus àtoms constituents en un sistema de coordenades i, per tant, la forma geomètrica de les eventuals molècules, definida mitjançant els angles que formen els àtoms i les distàncies que els separen.

No cal dir que per obtenir aquesta informació, la longitud d'ona de la radicació emprada ha de ser del mateix ordre de magnitud que la distància entre els àtoms o ions components del cristall. Per això cal treballar en l'àmbit dels raigs $X$.

Sense entrar en més detalls, cal esmentar que també es pot inferir informació estructural quan no es poden aïllar monocristalls, sinó tan sols pols microcristal-lina. Aleshores s'obtenen patrons de difracció angle de reflexió/intensitat que també poden informar sobre la seva estructura, tot i que de manera més limitada.

Fins i tot tractant-se de sòlids no cristal-lins, com els vidres, o de grans macromolècules biològiques o espècies catalítiques en solució, es poden esbri- nar detalls estructurals a nivell local, com ara nombre, naturalesa i distància radial entre àtoms a l'entorn immediat d'un altre; en aquest cas, mitjançant tècniques espectroscòpiques d'absorció de raigs $X$, cosa que ha esdevingut molt més factible atesa la gran intensitat de la llum de sincrotró.

Apart de les ja esmentades, altres tècniques avançades ofereixen noves possibilitats d'aplicació d'aquesta instal-lació, de gran interès en els camps de la física, de la química, la biologia molecular, les ciències ambientals, la geofísica, la medicina, la indústria farmacèutica i les indústries relacionades amb la ciència de materials (memòries informàtiques, materials magnètics, ciment, metal·lúrgia...).

Convé no oblidar l'ús de la llum de sincrotró en combinació amb tècniques litogràfiques tradicionals, en microelectrònica i recentment en micromecànica. (Ambdues esdevindran aviat nanotecnologies ! 1 nano $=10^{-3}$ micro). Per exemple, mitjançant raigs $X$ durs de sincrotró és possible microfabricar aparells minúsculs de microcirurgia o com els que servirien (fig. 8) per alliberar gradualment petites quantitats de medicament dins el cos d'un pacient.

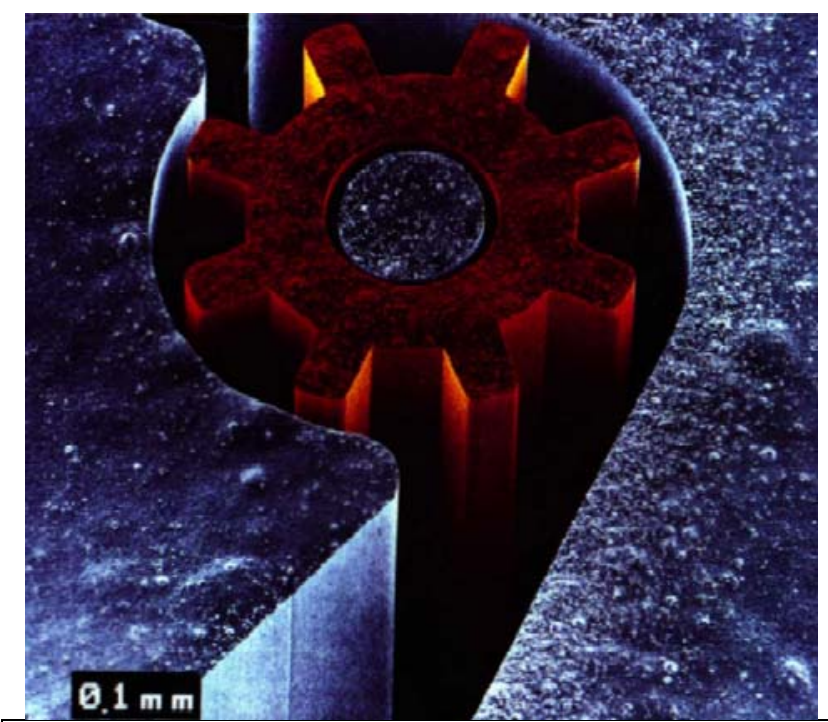

Fig. 8. Microdispositiu de bombament de fluids.

\section{SURT A COMPTE?}

El disseny i la construcció del sincrotró de Cerdanyola del Vallès està pressupostat en prop de 164 milions d'euros entre el 2003 i el 2008 (fig. 9). El manteniment de la instal-lació costarà uns 14 milions d'euros a partir del 2009.

Aquesta instal-lació, que donarà feina a 125 persones entre personal científic, tècnic i administratiu, es calcula que podrà ser utilitzada per més de 150 grups d'investigació espanyols, i d'uns 800 d'arreu d'Europa: universitats, centres de recerca, i també indústries... que pagarien els seus corresponents costos d'utilització. 


\section{Inversió, en milions d'euros}

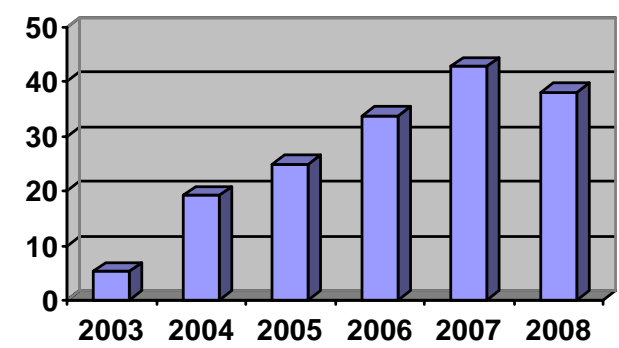

Fig. 9. Evolució de la inversió prevista en el sincrotró de Cerdanyola del Vallès.

En altres sincrotrons ja instal.lats fa anys, com el construït per diversos països europeus a Grenoble (França), i que està en funcionament des de 1992, s'ha constatat, a part d'un creixement en la recerca cientificotècnica tant a nivell bàsic com aplicat, una capacitat d'atracció i creació al seu voltant d'indústries basades en tecnologies avançades. Aquestes empreses, o bé participen com a auxiliars en el desenvolupament global del projecte del sincrotró, o bé s'han creat perquè en fan ús en els seus propis processos de fabricació. Tot plegat, un bon exemple de sinergia entre món industrial i centres de recerca.

El sincrotró català podria esdevenir, doncs, una bona eina per a potenciar la presència d'aquestes interessants indústries d'alta tecnologia al Vallès. Això contribuiria a dinamitzar tecnològicament i des d'un punt de vista socioeconòmic no solament el seu entorn geogràfic immediat, sinó, per extensió, l'economia de tot Catalunya.

Aquesta gran instal·lació científica s'anomenarà ALBA. No és un acrònim ni un nom a l'atzar. S'ha triat perquè el seu funcionament ha de significar el pas de la foscor a la llum, tant literalment com si d'una metàfora es tractés: se n'esperen uns resultats brillants!

\section{BIBLIOGRAFIA}

Pascual de Sans, Ramon (2003). "El projecte de font de llum de sincrotró al Vallès", Coneixement $i$ societat, 1, pp. 80-101 (Ed. DURSI).

http://www10.gencat.net/dursi/generados/catala/de partament/recurs/doc/01 art pascual.pdf 